\title{
APRESENTAÇÃO
}

\section{PSICANÁLISE E LINGUAGEM MÍTICA}

\author{
Jassanan Amoroso Dias Pastore
}

\begin{abstract}
A teoria das pulsões é, por assim dizer, nossa mitologia.
As pulsões são entidades míticas, magníficas em sua imprecisão.

Sigmund Freud (1).

Os mitos despertam no homem pensamentos que lhe são desconhecidos

Claude Lévi-Strauss.
\end{abstract}

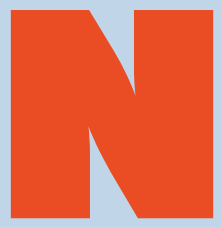

a aurora do século XX, em plena modernidade, Sigmund Freud extrai do corpus mítico grego, os alicerces para a fundação da psicanálise. Devemos ao autor a sensibilidade e a habilidade para transpor as fronteiras entre as idades da humanidade ao remontar à Grécia antiga, nosso berço, e pinçar em seus relatos míticos, em especial o mito de Édipo, elementos que servirão de matéria-prima para a elaboração de noções básicas desenvolvidas na psicanálise, como o complexo de Édipo. Conforme dramatizado em Édipo Rei, o sujeito é responsável por seus atos inconscientes ou não, o que instaura uma conexão entre a tragédia e a psicanálise.

Na biografia de Freud, o psicanalista Ernst Jones sublinha que, em toda a sua vida, o pai da psicanálise "provavelmente foi mais absorvido pelo grande problema de como o homem veio a ser homem do que por qualquer outra questão" (2). Impulsionado em direção a longínquas navegaçōes, Freud intui que o vento da história do processo de humanização - do devir homem -, sopra do passado.

Mircea Eliade (3), por sua vez, enfatiza que o cerne do mito é a origem das coisas, seus primórdios. O mito narra a origem do mundo, do homem, do animal, do fogo, da guerra etc. O autor considera que inclusive os mitos escatológicos giram em torno não do fim em si, mas de um novo começo.

Assim, um leque de aberturas se descortina ao estabelecermos uma comunhão entre mito e psicanálise. Pretendemos, por meio de um recorte, explorar como a psicanálise tem se nutrido do mito para pavimentar suas teorizações.

No princípio era o mythos

A palavra mito tem sua origem grega em mythos, que deriva do verbo mytheio, contar, narrar, e mytheo, contar, conversar.
$\mathrm{Na}$ Grécia arcaica, meados do século VIII ao século VI a. C., o sentido primordial do termo mythos era palavra ou discurso, atrelado a uma narrativa ligada aos deuses e heróis. Na literatura grega, mythos surge com o sentido de história ou narrativa a ser transmitida por meio da palavra. O narrador, um poeta/aedo escolhido pelos deuses, tem a palavra sagrada, pois advinda de uma revelação divina e, portanto, tomada como verdade.

Alguns pensadores sustentam que na Grécia arcaica, logos e mythos não se opunham; ambos se referiam a um relato sagrado transmitido oralmente, ao pé do ouvido, pela geração precedente à vindoura. Na Ilíada, por exemplo, palavra e logos aparecem como sinônimos. É somente a partir do advento da filosofia helênica, no século IV a. C., que se instaura uma antinomia entre os termos logos - argumentação racional -, e mythos.

O mito é, assim, um termo múltiplo desde sua raiz na língua grega, e se presta a designar as composições de diversos gêneros literários - o épico, o lírico e o dramático -, os relatos históricos, as lendas da tradição oral, bem como sua própria ordenação, isto é, os tipos de relação que se estabelecem entre os elementos constitutivos dos relatos.

Comumente, o mito é associado a estórias fabulosas, a narrativas fantásticas, muitas vezes, absurdas, incoerentes e contraditórias, impossíveis de terem lugar na vida real, porque se alojam na esfera do simbólico. Ernst Cassirer (4), ao defender a definição de homem como animal symbolicum, em vez de rationale, salienta que não só o pensamento científico se insere na dimensão simbólica, mas, também, a linguagem, o conhecimento mítico-religioso e a arte.

Em sua Poética (5), Aristóteles mostra-nos a ambiguidade etimológica em que está inserida a palavra grega mythos, que se refere a uma fabulação com intervenção de construções imaginárias, a um relato, a uma estória, ao mesmo tempo, que concerne ao arranjo desses fatos fabulosos, ao modo como eles se enredam.

Nessa perspectiva, é preciso atentar para o conteúdo do mito, como adverte o filósofo Gilbert Durand, também antropólogo e sociólogo, com vasta pesquisa em torno da ligação entre o universo simbólico e a civilização: "o que importa no mito não é exclusiva- 
mente o encadeamento da narrativa, mas também o sentido simbólico dos termos" (6).

Aristóteles, na mesma obra, situa o mito na intersecção entre o universal e o singular, entre a estrutura e sua atualização. O mito é passível de construção, reconstrução e atualização.

A ambiguidade etimológica do termo mito retrata a ambiguidade de sentido presente nos relatos míticos, em que o significado não pode ser considerado como unívoco e fixo, o que delimita um firme propósito de não considerarmos o mito como um arquétipo.

Em sua concepção de mito, o filósofo Ernst Cassirer, em seu livro Antropologia filosófica, escrito em 1944, nos esclarece que não podemos "reduzir o mito a certos elementos estáticos, fixos, mas procurar apreendê-lo em sua vida interior, em sua mobilidade e versatilidade, em seu princípio dinâmico" (7). Todo mito comporta uma miríade de versôes - o mar sem fim do presente.

Em 1958 é publicada a obra Antropologia estrutural, de Claude Lévi-Strauss. Nela, encontramos a ideia de que cada grupo social expressa, em suas construções míticas, suas atitudes em relação ao mundo, bem como as maneiras de lidar com os problemas da existência. Os mitos representam o patrimônio fantasmático de uma cultura, seus hábitos e costumes, e possui uma localização num tempo indeterminado.

$\mathrm{O}$ autor defende, também, que a sucessão de eventos de um mito não se sujeita a "nenhuma regra de lógica ou de continuidade" (8), e, portanto, qualquer sujeito pode possuir qualquer predicado, e qualquer relação concebível é possível.

Lévi-Strauss nos convida a pensar o mito à maneira como o linguista pensa a língua, ou seja, o mito como convivência entre os opostos de continuidade e descontinuidade, isto é, o desenvolvimento do mito é contínuo, mas sua estrutura é descontínua.

Contamos, nesse registro, com a colaboração de Ferdinand de Saussure, linguista e filósofo, que em Linguistica da língua e linguistica da fala (9), considera a linguagem composta por duas dimensōes complementares: a da língua: dimensão invariável e, portanto, estrutural, e a da fala: dimensão da contingência, da atualização pulsante e singular da língua (10).

Lévi-Strauss ainda ressalta o elemento de repetição de contradiçōes embutido na linguagem mítica. Ao enfatizar o aspecto contingencial do mito, o antropólogo leva em conta a similaridade das estórias em torno do mundo, mas em tempos diferentes da história - diversidade espaço-temporal. Há algo que se repete e que é, similarmente, insistente na linguagem mítica, mas que se encontra, ao mesmo tempo, entranhado em suas particularidades históricas e culturais. É o que leva Lévi-Strauss a afirmar que "um mito se compõe do conjunto de suas variantes" (11).

A repetição tem por efeito desvelar as contradições. Assim, o mito apresenta a recorrência de certas questōes conflitantes da humanidade: vida e morte; o mesmo e o outro; a diferença sexual; o perene e o transitório etc. Lévi-Strauss levanta que indagamos muitas vezes por que os mitos, e a literatura oral de modo geral, utilizam com tanta frequência a duplicação, a triplificação etc de uma mesma sequência. E, ele nos responde que a "repetição possui uma função própria, que é a de tornar manifesta a estrutura do mito" (12).

O inconsciente, a espinha dorsal da descoberta freudiana - a psicanálise e sua clínica - também se funda na figura do paradoxo, na coabitação de opostos, no conflito e na repetição - tendência de retorno ao mesmo ponto de origem, em geral, ao ponto de encontro com uma satisfação originária e absoluta, e, portanto, mortífera. Mas, o eterno retorno não significa sempre o retorno do idêntico. Ao contrário, voltar é ser, mas apenas o ser do devir, pois supõe um mundo em que as identificaçōes prévias são abolidas, dissolvidas, metamorfoseadas.

Écurioso notar que, etimologicamente, a palavra clínica originase do grego klinico, kline e do verbo klino, que significam tratamento, leito ou repouso, e deitar, reclinar, debruçar, inclinar. Asclépio, deus da medicina e filho de Apolo, no seu santuário, em Epidauro, transmite seus oráculos por meio dos sonhos. No ritual de cura por incubação, o doente é recebido para passar a noite a fim de ingressar no sono e incubar o sonho curativo.

Coube a Freud, em sua clínica, não por acaso, a invenção do artifício do divã, representante emblemático da posição privilegiada para as experiências de nascimento, doença, sexo, morte, sonho... dos pacientes. Deitar-se para relembrar, rememorar o que não pode ser esquecido é o convite de trabalho psíquico a ser realizado pelo analisando. E, aquilo que não se pode apagar, dá-se o nome em grego, de alétheia - não esquecimento -, traduzido também por desvelamento, verdade.

Alétheia, deusa da Verdade, faz par com Palavra cantada - Mồsa, as musas, Filhas da deusa Mnémosyne (Memória) -, com Luz e com Louvor. Nessa configuração de ordem mítico-religiosa, Alétheia-Verdade é potência criadora de ser (13). É desse tipo de verdade que se ocupam o mito e a psicanálise.

O objetivo fundamental do mito, seja ele grego ou não, é dar conta de contradiçóes, nos diz Lévi-Strauss. E, ao nos referirmos à questão da verdade trazemos com ela a sua antítese, ou seja, o esquecimento - Léthe, em grego, cúmplice do silêncio, de censura e de obscuridade.

Os gregos antigos acreditam que o registro dos ensinamentos de outros tempos, dos grandes homens e povos deveria ser lembrado, e que essas lembranças levam às verdades da vida que o homem deve sempre buscar e preservar.

Marcel Detienne (14) lembra-nos que ao final do século IV a. C., na Grécia arcaica, uma espécie de ritual báquico e órfico testemunha a força escritural dos meios filosófico-religiosos fascinados pelos jogos da memória, do esquecimento e da verdade. Às margens do mar Negro, escavadores soviéticos encontram em tabuinhas de osso, grafites datados de 500 a. C.: ao lado da palavra órfica, aparecem Dioniso, Verdade (Alétheia), sob os três termos Vida-Morte-Vida. Na segunda plaqueta, ao lado do par Paz-Guerra, lê-se Verdade-Engano (Alétheia-Pseudos). Em uma terceira ta- 
buinha, sob o nome de Dioniso abreviado, aparece a Alma, Psyché, associada à Alethéia.

Encontramos, portanto, desde os tempos arcaicos, a indelével presença não só de Dioniso - o deus da contradição -, como também da memória no mito grego, e, mais recentemente, na clínica psicanalítica. Porém, lembremos que as musas podem escolher entre dizer a verdade ou a mentira: "sabemos muitas mentiras dizer símeis aos fatos/e sabemos, se queremos, dar a ouvir revelaçōes (Alethéia)" (15), ou seja, o canto/fala das musas transita entre o falso e o verdadeiro, entre a ficção e a verdade, ou melhor, se localiza na verdade como ficção. Memória, por sua vez, requer outro alguém que a ouça, e seu canto/fala gravita em torno do que foi, na visada do que será: "Eia! pelas Musas comecemos, (...)/dizendo o presente, o futuro e o passado"(16).

Freud salienta que o psiquismo não se restringe ao indivíduo, e que a vida humana é tecida entre o coletivo e o individual. O inconsciente, embora atemporal, traz as marcas da memória da espécie e da história, que recaem sobre o destino individual.

A partir do par antitético, mas dialético, verdade-esquecimento, Lévi-Strauss esclarece que há já muita psicanálise no mito. O mito está intimamente ligado à noção de verdade, verdade essa velada no interior do próprio mito. É o anúncio de um dos princípios fundamentais da psicanálise, o princípio da dualidade como estruturante da vida psíquica.

Freud recomenda a nós, psicanalistas, não só a inclusão de um curso de mitologia na formação psicanalítica, como também a relevância em conhecermos o desenvolvimento da linguagem - a etimologia - ao trabalharmos na tradução da linguagem do sonho.

Na psicanálise, desde os seus primórdios em 1900, com a obra fundante do método psicanalítico, $A$ interpretação dos sonhos (17), o mito figura como objeto de fascínio, como fonte ímpar de inspiração e reflexão para Freud pavimentar suas teorias acerca do funcionamento psíquico. Nesse texto, o mito aparece como via de compreensão para os processos inconscientes. A linguagem dos oráculos é ambígua e se aproxima da linguagem dos sonhos, uma vez que o oráculo indica os desígnios, mas fica a cargo do homem a sua interpretação. O sonho, à semelhança do mito, abarca a projeção de desejos inconscientes de um sonhador particular. Portanto, o mito expressa o sonho da humanidade, ao passo que o sonho de um sujeito designa seu mito singular, ou, o mito individual do neurótico, segundo Jacques Lacan (18). O mito é um saber que nos atravessa sem que o saibamos, assim como o inconsciente é um saber que não se sabe que se sabe.

A psicanálise, ao tratar da análise da realidade psíquica, institui na travessia em direção ao processo de subjetivação, o caminho da construção de uma linguagem mitopoiética. Hódos, em grego, significa caminho, de onde deriva méthodos, busca de algo, especialmente de saber, de conhecimento que se refere, também, ao modo como essa busca é conduzida.

Em seu trabalho clássico Totem e tabu (19), Freud se utiliza de vasta informação antropológica da época, inclusive da magnífica obra $O$ ramo de ouro (20), do evolucionista James George Frazer, que contém os mitos provenientes do mundo inteiro, conferindo um lugar privile- giado aos relatos míticos de autores gregos e latinos, a fim de confrontá-los com os dos povos primitivos. Sua investigação se orienta para o ritual, a memória, o inconsciente social e, também, para uma reflexão sobre o poder e os modelos da transmissão, ou seja, sobre as relações entre o simbólico e o poder. Na psicanálise, Freud constrói o mito da horda primitiva - o banquete totêmico e a matança do pai primevo/ tirânico, detentor de tudo, de todas as filhas e mulheres, pelos filhos-, por meio da análise dos ritos e crenças do totemismo e do animismo. A partir desse mito é elaborada uma compreensão psicanalítica sobre a origem da cultura e de suas restriçôes morais e religiosas. Freud trata das imperiosas pulsões psíquicas envolvidas nos vínculos entre pais e filhos e, por extensão, entre os seres humanos em geral, erigindo a existência da lei psíquica primordial, que a humanidade está submetida, atrelada à função de barrar o excesso pulsional. Dualidade entre as pulsôes sexuais e as de destruição. Conflito entre Eros e Tânatos. Portanto, o desejo e sua proibição andam de mãos dadas, legado que Freud assimilou dos mitos.

Freud não abandona o mito até o final de sua obra, como vemos em seu último trabalho publicado, Moisés e o monoteísmo (21), embora escrito em dois momentos distintos: o primeiro em 1937, em Viena, e o segundo em 1938, já em Londres. Nele, Freud retoma e condensa os elementos fundamentais de seus escritos precedentes que tratam da cultura e da religião. $\mathrm{O}$ mito fundador da cultura - mito da horda primeva - é realocado sob os signos da tradição judaica, e é levantada a presença, na nossa civilização, dos mitos subjacentes à religião judaico-cristã. A lei moral alcança, nesse texto, o seu acabamento final, agora vinculada à trama judaico-cristã. Mas, o que vem a ser isso? Isso lança-nos à hipótese freudiana de que os deuses pagãos do mundo grego serão substituídos pelo pai da religião judaico-cristã. Digo hipótese porque essa obra é classificada, pelo próprio Freud, textualmente, como "romance histórico", como a reconstrução de um novo mito, que instaura uma articulação entre o verdadeiro e o falso, entre a ciência e a arte. Decorre daí que, destituído o paganismo grego que está submetido ao imperativo do destino, não mais podemos culpar os deuses pelos nossos infortúnios, e o homem se torna responsável pelo seu inconsciente.

Durante toda sua obra, talvez Freud tenha seguido atrás de seu próprio mito, até que, em seu Moisés, ele realiza a sua consumação, ao escrever e elaborar sua relação com o pai. E esse é o grande mérito desse texto.

O mito freudiano do Moisésé tecido quando Freud está, mais uma vez, mergulhado na questão da subjetividade e, consequentemente, da cultura. Num (des)acerto de contas entre o criador e a criatura, Freud reforça a função paterna como constitutiva do simbólico.

Podemos dizer que, na modernidade, a maioria das nossas verdades científicas, assim como muitas das nossas concepçōes morais, políticas e filosóficas são apenas novas concepçōes de tendências que antes encarnaram em formas míticas.

O homem contemporâneo, à diferença do homem psicanalítico, racionalizou os mitos, mas não pôde eliminá-los!

Jassanan Amoroso Dias Pastore épsicanalista, membro efetivo da Sociedade Brasileira de Psicanálise de São Paulo, da International Psychoanalytical Association e do Departamento de Psicanálise do Instituto Sedes Sapientiae. 


\section{REFERÊNCIAS BIBLIOGRÁFICAS}

1. Freud, S. (1933). "Novas conferências introdutórias à psicanálise". In: Edição standard brasileira das obras psicológicas completas de Sigmund Freud (J. Salomão, trad., Vol. 22). Rio de Janeiro: Imago, p. 56, 1974.

2. Jones, E. A vida e a obra de Sigmund Freud, Rio de Janeiro: Imago, p. 297, 1979.

3. Eliade, M. Aspecto do mito. Lisboa: Edições 70, 2000.

4. Cassirer, E. Filosofia de las formas simbólicas. México: Fondo de Cultura Economica, 1998.

5. Aristóteles. Poética (Eudoro de Sousa, trad.). Rio de Janeiro/Porto Alegre: Ed. Globo, 1966.

6. Durand, G. Imaginação simbólica. São Paulo: Cultrix, 1988.

7. Cassirer, E. Antropologia filosófica, São Paulo: Mestre Jou, p. 127, 1972.

8. Lévi-Strauss, C. Antropologia estrutural, São Paulo: Cosac Naify, p. 223, 2008.

9. Saussure, F. "Linguística da língua e linguística da fala". In: Curso de linguística geral. São Paulo: Cultrix, p. 27, 2006.

10. Azevedo, A.V. de. Mito e psicanálise. Rio de Janeiro: Jorge Zahar, p. 2004.

11. Lévi-Strauss, C. Antropologia estrutural, São Paulo: Cosac Naify, p. 234, 2008.

12. Lévi-Strauss, C. op. cit. p. 247, 2008.

13. Detienne, M. Os gregos e nós. Uma antropologia comparada da Grécia Antiga. São Paulo: Edições Loyola, p. 77, 2008.

14. Detienne, M. op. cit. p. 88, 2008.

15. Hesíodo. Teogonia (Jaa Torrano, trad.), São Paulo: lluminuras, p. 103, vv. 27-28, 2007.

16. Hesíodo. op. cit. p. 105, vv. 36-38, 2007.

17. Freud, S. (1900). "Interpretação dos sonhos". In: Edição standard brasileira das obras psicológicas completas de Sigmund Freud (J. Salomão, trad., Vol. 4-5). Rio de Janeiro: Imago. 1974.

18. Lacan. J. O mito individual do neurótico, ou, a poesia e verdade na neurose (Claudia Berliner, trad.). Rio de Janeiro: Jorge Zahar, 2008.

19. Freud, S. (1913). "Totem e tabu". In: Edição standard brasileira das obras psicológicas completas de Sigmund Freud (J. Salomão, trad., Vol. 13). Rio de Janeiro: Imago. 1974.

20. Frazer, J. G. O ramo de ouro. Rio de Janeiro: Zahar, 1982.

21. Freud, S. (1939). "Moisés e o monoteísmo". In: Edição standard brasileira das obras psicológicas completas de Sigmund Freud (J. Salomão, trad., Vol. 23). Rio de Janeiro: Imago. 1974. 